\title{
The learning transfer system approach to estimating the benefits of training: empirical evidence
}

\author{
Paul Donovan \\ Irish Management Institute, Dublin, Ireland \\ Kevin Hannigan \\ Irish Management Institute, Dublin, Ireland \\ Deirdre Crowe \\ Irish Management Institute, Dublin, Ireland
}

\section{Keywords}

Training, Evaluation, Benefits

\begin{abstract}
Three steps must be implemented if a training programme is to be successful. The first is the identification of needs to identify what training is required. The second is an analysis of the firm to identify the issues that will affect the ability of the firm to exploit new skills. The third is an evaluation of the training to ensure that sufficient resources are applied to implement and to integrate the training programme. These latter two steps come under the heading of learning transfer. The article presents the findings of an application of this approach.

The analysis shows the richness of the information that results from this approach and outlines its operational importance for managers engaged in decisionmaking or in the design of training programmes. In addition, it suggests the next steps in the research towards improving the tools available for the evaluation of training.
\end{abstract}

\section{Approaches to the evaluation of training}

In the current climate of globalisation, heightened competition and the development of information technology the paradigm for success has shifted towards intellectual assets. Increasingly, the key source of competitiveness in firms is the ability to develop and use the skills of their workforce. The central role of knowledge and skills in wealth creation and the modern economy is expressed by Eliasson (1994, p. 177) who states:

Human competence dominates economic performance at all levels. Its hallmark is heterogeneity to the extent that in each agent certain dimensions of it are unique and not (directly) imitable or communicable.

New forms of business structure and management are required to effectively exploit intellectual assets leading to a renewed focus on the development of human resources. At the same time the pace of change has quickened leading to a growing emphasis on the need for continuous upskilling.

Training requires substantial allocation of financial, human and time resources. Yet, despite the substantial investment of valuable resources, the information and skills that are learned in training may never actually be applied in the workplace. Whether or not transfer of learning takes place depends on many factors including employee motivation, relevance of training and, notably, the work environment. Consequently, it is important that training needs are assessed and outcomes evaluated as comprehensively as possibly.

The inadequacies of traditional approaches to evaluating the benefits of training

Journal of European Industrial Training

25/2/3/4 [2001] 221-228

(C) MCB University Press [ISSN 0309-0590] programmes are discussed in-depth in

The research register for this journal is available at http://www.mcbup.com/research_registers
Hannigan et al. (2000). Economic approaches tend to focus on productivity and the return on investment. The models have proven inadequate in assessing the effectiveness of training mainly because they ignore the individual firm context. Traditional HRD evaluation models, which focus on the individual training programme, are also limited and have been dominated by the Kirkpatrick four-level model for the past 40 years (Kirkpatrick, 1996).

Holton (1996) proposed an alternative, more comprehensive model which might be labelled the "influences" approach. The model was based on a weaving together of existing work in the area. This model, although complex, suggested that alternative strategies might be possible to enable the development of practical evaluation tools that were grounded in theory (Figure 1). Major intervening variables that affect learning such as trainee readiness, motivation, training design and reinforcement of training on the job are not specified in the Kirkpatrick (1996) four-level model. In addition, individual differences which may also affect training outcomes are not accounted for. This has the potential to lead to faulty decisions about HRD intervention effectiveness (Holton, 1996; Swanson and Holton, 1999). This paper presents the findings of an application of this model.

Holton's model is holistic in its approach and moves the debate away from a concentration on outcomes to a discussion about how training works and how the factors that make it work can be enhanced in the organisation. By doing so it avoids the weaknesses that were identified in the case of outcomes-based models that assumed simple relationships and causal linkages were in place. 
Paul Donovan, Kevin Hannigan and Deirdre Crowe

The learning transfer system approach to estimating the

benefits of training: empirical evidence

Journal of European Industrial Training

25/2/3/4 [2001] 221-228

\section{Figure 1}

Holton's evaluation model

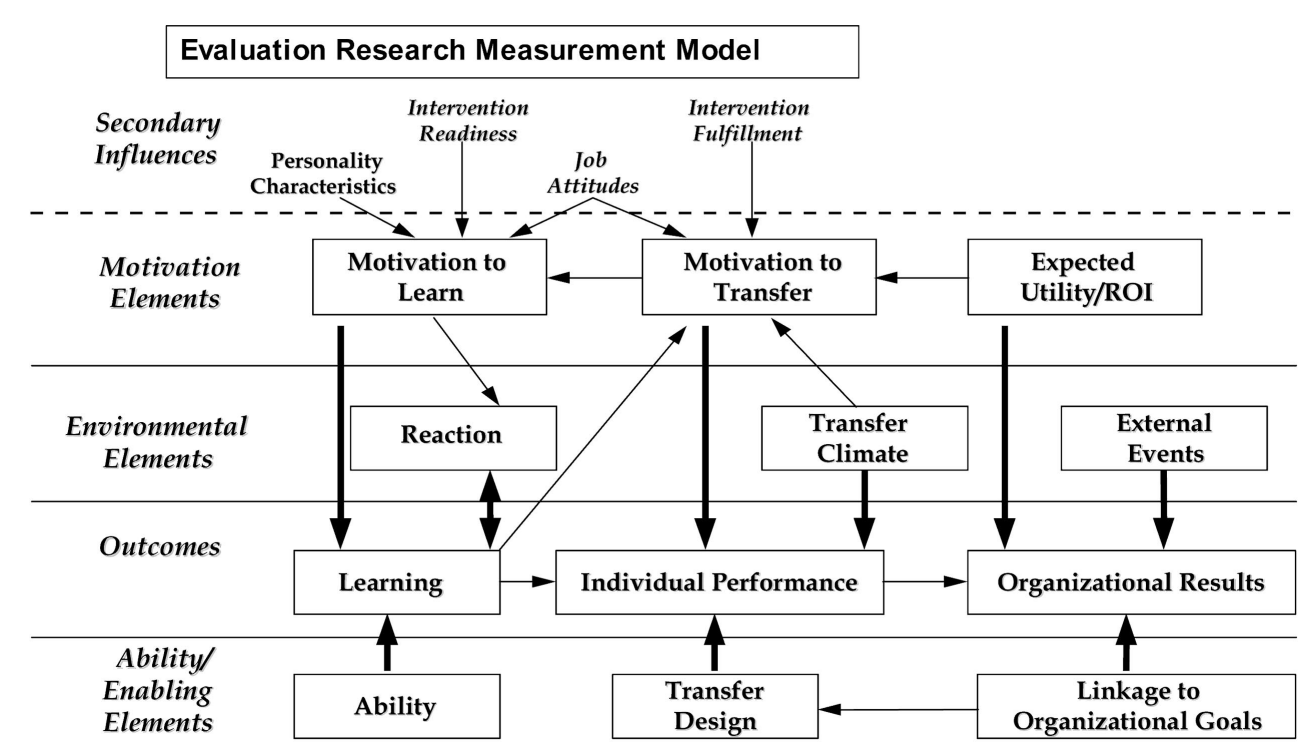

The learning transfer system approach

Much work has been done on the transfer of learning into the workplace from training interventions. Several influences on the motivation to transfer have been identified including intervention fulfilment, learning outcomes, job attitudes, and expected utility of results (Broad and Newstrom, 1992; Baldwin and Ford, 1998). Holton et al. (1999) encapsulate these approaches most successfully in their conceptual model of learning transfer systems.

The learning transfer system is described as those organisational supports and constraints that influence whether participants take what they learn in the training environment and transfer it to the work environment. It describes one critical portion of the overarching Holton (1996) model, the transfer of learning into individual performance. Based on this model, the learning transfer system inventory (LTSI) was developed to assess practically these factors in the workplace (Holton et al., 1999). Sixteen factors that influence transfer were identified and validated using common factor analysis on a large and diverse sample. This system is shown in Figure 2 and Table I gives a brief description of each factor.

Some of the 16 factors refer to the transfer of learning in the organisation in general and some to the specific training intervention. Attitudes, preparation and the transfer climate may differ between different types of training such as management versus technical or between different departments and teams. The LTSI will enable and organisation to identify the factors which make some training programmes more successful than others and, over time, a comprehensive profile of the organisation can be elaborated.

The 16 factors are grouped into four scales in Figure 2:

1 ability to use knowledge and expertise;

2 motivation to use knowledge and expertise;

3 work environment supporting use of knowledge and expertise;

4 trainee characteristics (secondary elements).

In practice, the LTSI is a questionnaire presented to participants at the end of their training course/programme. Respondents indicate, on a Likert scale, the extent to which they agree or not with a series of statements and answers are scored from 1 (strongly disagree) to 5 (strongly agree). These answers are compiled to give factor scores, again in a range of 1 to 5 . In effect, scores below 2.5 are deemed to be negative, 2.5 to 3.5 are neutral and 3.5 to 5 positive (Table II).

As well a giving factor results, issues within each factor can be identified and highlighted. Based on the answers to individual questions, negative, neutral and positive issues enable greater depth and subtlety in the interpretation of results. The results are used to assess the quality of the transfer climate and to indicate where changes may need to be made in order to promote the effective use of training. They are the basis for in-depth analysis and clear, concise recommendations for the 
Paul Donovan, Kevin Hannigan and Deirdre Crowe

The learning transfer system approach to estimating the benefits of training: empirical evidence

Journal of European Industrial Training

25/2/3/4 [2001] 221-228 organisation. This enables organisations to target areas in need of improvement in order to capitalise fully on investment in training.

\section{Empirical application of the learning transfer system inventory}

A total of 158 respondents from a management training programme (MTP) of a large international organisation completed the inventory. The results are detailed in Table III. These show the following positive results:

- Employees are confident, open to change and supportive of each other.

- They are motivated to apply learning and expect to achieve improved performance as a result.

- They have the time and energy to implement new skills as well as the necessary human, financial and physical resources.

- They do not experience supervisor/ manager sanctions when implementing new learning.

Negative/neutral results were also recorded:

- Implementation of new learning on the job is not perceived to lead to positive outcomes for the individual.

- Failure to apply new learning is not seen to be noticed or dealt with.

- Trainees receive little supervisor/ managerial consultation/support either before or after training. They are not well briefed or prepared for training.

\section{$\overline{\text { Figure } 2}$}

The learning transfer system inventory

\begin{tabular}{|c|c|c|c|c|}
\hline$\frac{\text { Secondary }}{\underline{\text { Influences }}}$ & \multicolumn{4}{|c|}{ Performance Self-Efficacy } \\
\hline Motivation & \multicolumn{4}{|c|}{$\begin{array}{l}\text { Motivation to Transfer } \\
\text { Transfer Effort } \rightarrow \text { Performance } \\
\text { Performance } \rightarrow \text { Outcomes }\end{array}$} \\
\hline Environment & \multicolumn{2}{|r|}{$\begin{array}{l}\text { Feedback } \\
\text { Peer Support } \\
\text { Supervisor Support } \\
\text { Openness to Change }\end{array}$} & \multicolumn{2}{|c|}{$\begin{array}{l}\text { Personal Outcomes - Positive } \\
\text { Personal Outcomes - } \\
\text { Negative } \\
\text { Supervisor Sanctions }\end{array}$} \\
\hline Outcomes & Learning & $\begin{array}{l}\text { Indivic } \\
\text { Perforn }\end{array}$ & & $\begin{array}{c}\text { Organisational } \\
\text { Performance }\end{array}$ \\
\hline$\underline{\text { Ability }}$ & & $\begin{array}{l}\text { Content V } \\
\text { Transfer D } \\
\text { Personal C } \\
\text { Opportuni }\end{array}$ & $\begin{array}{l}\text { ity } \\
\text { gn } \\
\text { icit } \\
\text { U }\end{array}$ & \\
\hline
\end{tabular}

Source: Holton et al. (1999). Figure is copyright Holton and Bates.
- The training content is not clearly relevant.

- Employees do not associate improved performance with positive outcomes or reward although it may be noticed/ valued.

Based on these LTSI findings, recommendations can be made to the company that has undertaken the training. In this case, the company expressed confidence that the results accurately reflected the organisation's culture and experience. This is a very positive and encouraging finding. However, further validation is on-going and a survey is being prepared which will link perceived training outcomes with LTSI results.

\section{Influencing variables: status and years of service}

Further analysis of the data was undertaken to discover if underlying variables could be identified that had predictive power regarding the ability of employees to transfer learning. Two of these, "Employment status" and "Years of service", were found to be particularly relevant. Table IV illustrates the breakdown of management training programme (MTP) participants in relation to their status. Approximately one-third are classed as "Continuing appointment" staff (permanent contract), one-third are international, and over one-quarter are staff on fixed term contracts.

Table V contains statistical means for respondents of differing status. Continuing appointment respondents are more positive about their capacity to transfer learning in terms of workload, schedule, personal energy etc. than non-continuing appointment respondents. Fixed term respondents are less likely to receive feedback and performance coaching than non-fixed term respondents. International respondents are less likely to encounter supervisor/manager sanctions when they implement new skills and techniques when compared to noninternational (national) respondents.

The years of service variable is also significant in the case of several factors (Table VI). One-fifth of respondents were in the organisation for 15 years or more and one-fifth for less than five years. Almost half were in the organisation for five to 11 years. Those who had been serving the longest were more prepared for training and believed the training content to be more relevant to their job requirements. They also perceived their workgroup to be more open to change and were more confident about their own ability 
Paul Donovan, Kevin Hannigan and Deirdre Crowe

The learning transfer system approach to estimating the

benefits of training: empirical

evidence

Journal of European Industrial

Training

25/2/3/4 [2001] 221-228 $\overline{\text { Table I }}$

Brief descriptions of the 16 factors measured by the learning transfer system inventory

Ability to use knowledge and expertise

Personal capacity for transfer How individuals' workload, schedule, personal energy and stress-level facilitate or inhibit transfer of learning into the workplace

Perceived content validity

The degree to which skills and knowledge taught in training are similar to performance expectations as well as to what is needed to perform more effectively. Similarity of methods and materials to those used in the work environment

Transfer design

Does the training programme clearly link learning with on-the-job performance and demonstrate how to apply new knowledge and skills?

Opportunity to use learning Does the organisation provide individuals with opportunities to apply new skills? Is there adequate provision of resources to apply new skills such as equipment, information and materials as well as financial and human resources?

\section{Motivation to use knowledge and expertise}

Motivation to transfer learning Are trainees motivated to utilise learning? To what degree do individuals feel able to perform and believe new skills will help them to more effectively perform onthe-job?

Performance - outcomes expectations

This is a measure of whether individuals believe that applying learned skills and knowledge will lead to recognition/rewards they value. Does the organisation create an environment in which individuals feel good about performing well?

Transfer effort - performance Do individuals believe that applying skills and knowledge learned in training will expectations improve their performance? How have efforts to utilise new skills made a difference in the past and will such efforts affect future productivity and effectiveness?

Work environment designed to support use of knowledge and expertise

Personal outcomes - positive What positive outcomes exist for the individual as a result of applying training on the job?

Personal outcomes - negative Are there any outcomes for the individual as a result of not applying training on the job? Negative outcomes include: reprimands; cautions; and penalties. It also indicates whether it is noticed or not if employees do not use their training

Peer support Do colleagues mutually appreciate and encourage the use of new skills learned in training? Do colleagues expect new learning to be applied and do they show patience when new skills and techniques are tried out?

Supervisor/manager support To what extent are managers/supervisors involved in: clarifying performance expectations after training; identifying opportunities to apply new skills and knowledge; setting realistic goals based on training; working with individuals on problems encountered while applying new skills; and providing feedback when individuals successfully apply new abilities?

Supervisor/manager sanctions

Do individuals perceive negative responses/opposition from managers/ supervisors when applying new skills? Do they assist in identifying opportunities to apply new skills and knowledge?

Openness to change This factor surveys individuals' perception of their workgroups' resistance to change, willingness to invest energy for change, and the degree of support provided by the workgroup to individuals who use techniques learned in training

Feedback/performance coaching

Do individuals receive indicators from people in their work environment (colleagues, managers, employees) about their job performance? These indicators may be formal and/or informal such as constructive input, assistance and feedback from people

Trainee characteristics - secondary elements

Learner readiness

How well were individuals prepared for training? Did they have opportunity to provide input prior to training? Did they know what to expect during training and did they understand how training was relevant to their work performance and job-related development?

Performance self efficacy
Are individuals confident and self-assured about applying new abilities and overcoming obstacles that hinder the use of new knowledge and skills? 
Paul Donovan, Kevin Hannigan and Deirdre Crowe

The learning transfer system approach to estimating the

benefits of training: empirical

evidence

Journal of European Industrial

Training

25/2/3/4 [2001] 221-228

$3.5-4$

\section{$>4-5$}

Interpretation of LTSI factor scores

\begin{tabular}{ll}
\hline Factor score & Result \\
\hline $\mathbf{1 - 2}$ & Extremely negative \\
$\mathbf{2 - 2 . 4}$ & Negative \\
$\mathbf{2 . 5 - 3 . 4}$ & Neutral \\
$\mathbf{3 . 5 - 4}$ & Positive \\
$\mathbf{> 4 - 5}$ & Extremely positive \\
\hline
\end{tabular}

to overcome obstacles and to implement new training. Conversely, opportunity to use learning was more positive among those in the organisation six to 11 years. $\overline{\text { Table IV }}$

Status of MTP respondents $(n=158)$

\begin{tabular}{lcc}
\hline & No. & Percent \\
\hline Continuing appointment & 50 & 32 \\
Fixed term contract & 42 & 27 \\
International & 53 & 34 \\
\hline
\end{tabular}

This analysis is of more than academic interest. It suggests that some planned segregation of employees before training, and plans drawn up accordingly, may be useful in promoting learning transfer. However, these are tentative findings at this stage.

\section{Table III}

LTSI factor scores for case example management training programme $(n=158)$ : negative/neutral/positive results

\begin{tabular}{|c|c|c|c|}
\hline Factor & Score & Result & Comment \\
\hline \multicolumn{4}{|l|}{ Ability } \\
\hline Perceived content validity & 3.3 & Neutral & $\begin{array}{l}\text { It suggests that the training content did not clearly enough reflect job } \\
\text { requirements }\end{array}$ \\
\hline Personal capacity for transfer & 3.5 & Positive & $\begin{array}{l}\text { This suggests that employees, to a certain extent, have the time, energy and } \\
\text { mental space in their work lives to make the changes required to transfer } \\
\text { learning to their job }\end{array}$ \\
\hline Opportunity to use learning & 3.5 & Positive & $\begin{array}{l}\text { It indicates that employees are likely to be provided with resources and obtain } \\
\text { tasks on the job which enable them to use skills learned in training }\end{array}$ \\
\hline Transfer design & 3.6 & Positive & $\begin{array}{l}\text { To a certain extent, training enables employees to apply learning to their jobs and } \\
\text { the instruction matches job requirements }\end{array}$ \\
\hline
\end{tabular}

\section{Motivation}

Performance - outcomes expectations

Motivation to transfer learning

Transfer effort - performance expectations

Work environment

Personal outcomes - negative

Personal outcomes - positive

Supervisor/manager support

Feedback/performance coaching

Peer support

Openness to change

Supervisor/manager sanctions

Trainee characteristics

Learner readiness

Performance self efficacy
3.3 Neutral Employees do not clearly believe that improvements in job performance lead to outcomes they value

3.8 Positive Employees show some direction, intensity and persistence in utilising skills and knowledge learned in training

3.9 Positive Employees believe that effort devoted to transferring learning will lead to changes in job performance

2.2 Negative Employees believe that failure to apply new skills and learning will not be noticed or result in negative outcomes for themselves

2.3 Negative Employees do not see positive outcomes as a result of applying new skills and learning on the job

3.0 Neutral It means that managers/supervisors do not usually react negatively to the use of new skills, knowledge or techniques by employees

3.0 Neutral It indicates that individuals do not clearly receive feedback, instruction or performance indicators from the people in their workplace

3.5 Positive Colleagues usually reinforce and support use of learning on the job. They show some patience and appreciation when new skills and techniques are tried and used

3.7 Positive Employees mainly perceive their workgroup to be open to, supportive of and willing to invest effort in change and to try new ways of doing things

3.8 Positive It means that managers/supervisors do not usually react negatively to the use of new skills, knowledge or techniques by employees

3.2 Neutral In general, employees were not clearly prepared for training. Prior to training, they did not know what to expect or how training was related to their job development or should affect performance

3.8 Positive Employees are self-confident and believe in their own ability to change their performance if they want to and to overcome obstacles that may hinder the use of new learning 
Paul Donovan, Kevin Hannigan and Deirdre Crowe

The learning transfer system approach to estimating the

benefits of training: empirical evidence

Journal of European Industrial Training

25/2/3/4 [2001] 221-228

Ability scale

Mean result

$$
(n=49)
$$

3.7 positive

Status

$t$ value

df

Significance

\section{Perceived content validity}

Ability scale

Mean result

3.3 neutral

Fixed term

$(n=41)$

3.2 neutral

$$
(n=112)
$$

3.4 neutral

2.06

151

Supervisor/manager sanctions

Work environment scale

Mean result $\quad 3.8$ positive

International

Non-international

$(n=53)$

4.0 extremely

positive

$$
(n=101)
$$

3.7 positive $\quad-0.2781 \quad 152$

Notes: $* p<0.05 ; * * p<0.01$

\begin{tabular}{|c|c|c|c|c|c|c|c|c|c|c|c|}
\hline \multirow[b]{2}{*}{ Years } & \multirow[b]{2}{*}{$\%$} & \multicolumn{2}{|c|}{ Learner readiness } & \multicolumn{2}{|c|}{ Content validity } & \multicolumn{2}{|c|}{ Opportunity to use } & \multicolumn{2}{|c|}{ Openness to change } & \multicolumn{2}{|c|}{ Own efficacy } \\
\hline & & Mean & Result & Mean & Result & Mean & Result & Mean & Result & Mean & Result \\
\hline$<5$ & 20 & 3.1 & Neutral & 3.1 & Neutral & 3.4 & Neutral & 3.4 & Neutral & 3.6 & Positive \\
\hline $5-9$ & 38 & 3.2 & Neutral & 3.4 & Neutral & 3.7 & Positive & 3.7 & Positive & 3.9 & Positive \\
\hline $10-14$ & 22 & 3.0 & Neutral & 3.2 & Neutral & 3.5 & Neutral & 3.7 & Positive & 3.7 & Positive \\
\hline $15+$ & 19 & 3.4 & Neutral & 3.6 & Positive & 3.4 & Neutral & 3.8 & Positive & 3.9 & Positive \\
\hline Total & 100 & 3.2 & Neutral & 3.3 & Neutral & 3.5 & Positive & 3.7 & Positive & 3.8 & Positive \\
\hline $\mathbf{F}$ & & & 2.221 & & 4.177 & & 2.523 & & 3.109 & & 2.433 \\
\hline \multicolumn{2}{|c|}{ Significance } & & n.s. & & $* *$ & & n.s. & & $*$ & & n.s. \\
\hline$<2$ & 12 & 2.8 & Neutral & 2.9 & Neutral & 3.4 & Neutral & 3.4 & Neutral & 3.5 & Positive \\
\hline $2-5$ & 16 & 3.1 & Neutral & 3.1 & Neutral & 3.4 & Neutral & 3.4 & Neutral & 3.7 & Positive \\
\hline $6-11$ & 45 & 3.2 & Neutral & 3.4 & Neutral & 3.7 & Positive & 3.7 & Positive & 3.9 & Positive \\
\hline $12-18$ & 19 & 3.1 & Neutral & 3.4 & Neutral & 3.4 & Neutral & 3.7 & Positive & 3.7 & Positive \\
\hline $19+$ & 9 & 3.7 & Positive & 3.5 & Positive & 3.3 & Neutral & 3.9 & Positive & 4.1 & $\begin{array}{c}\text { Extremely } \\
\text { positive }\end{array}$ \\
\hline Total & 100 & 3.2 & Neutral & 3.3 & Neutral & 3.5 & Positive & 3.7 & Positive & 3.8 & Positive \\
\hline $\mathbf{F}$ & & & 3.031 & & 2.865 & & 3.217 & & 2.024 & & 3.611 \\
\hline Signific & & & $*$ & & $*$ & & $*$ & & n.s. & & $* *$ \\
\hline
\end{tabular}

\section{$\overline{\text { Table VI }}$}

Years of service for MTP respondents

Notes: $* p<0.01 ; * * p<0.05$

\section{Table VII}

Description of companies in sample

\begin{tabular}{llll}
\hline Company & Description & Country & Type of training \\
\hline $\mathbf{1}$ & Manufacturing - technology & USA (in Ireland) & Supervisor \\
$\mathbf{2}$ & Service - semi-state & Ireland & Supervisor \\
$\mathbf{3}$ & Service - local authority & Ireland & Supervisor \\
$\mathbf{4}$ & Manufacturing - technology & USA (in Ireland) & Supervisor \\
$\mathbf{5}$ & International organisation & International & Management \\
$\mathbf{6}$ & Service ex-semi-state & UK & Management \\
\hline
\end{tabular}

\section{Comparison with other training programmes}

The LTSI has been administered in a number of other organisations as part of this research also (Table VII). The results for a selection of factors for some are shown in Tables VIII and IX.

Some factors are shown to differ significantly between companies. However, there is also considerable similarity emerging. In summary, employees are willing and accepting of learning and, while they perceive that training programmes are 
$\overline{\text { Paul Donovan, Kevin Hannigan }}$ and Deirdre Crowe

The learning transfer system approach to estimating the

benefits of training: empirical evidence

Journal of European Industrial Training

25/2/3/4 [2001] 221-228

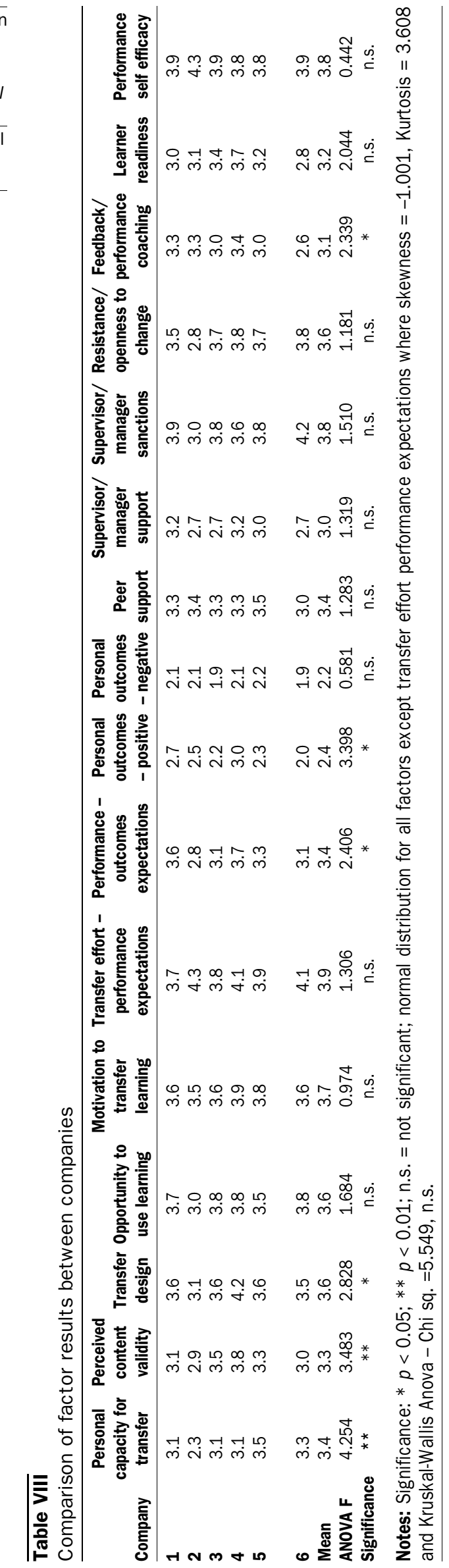

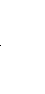

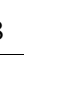

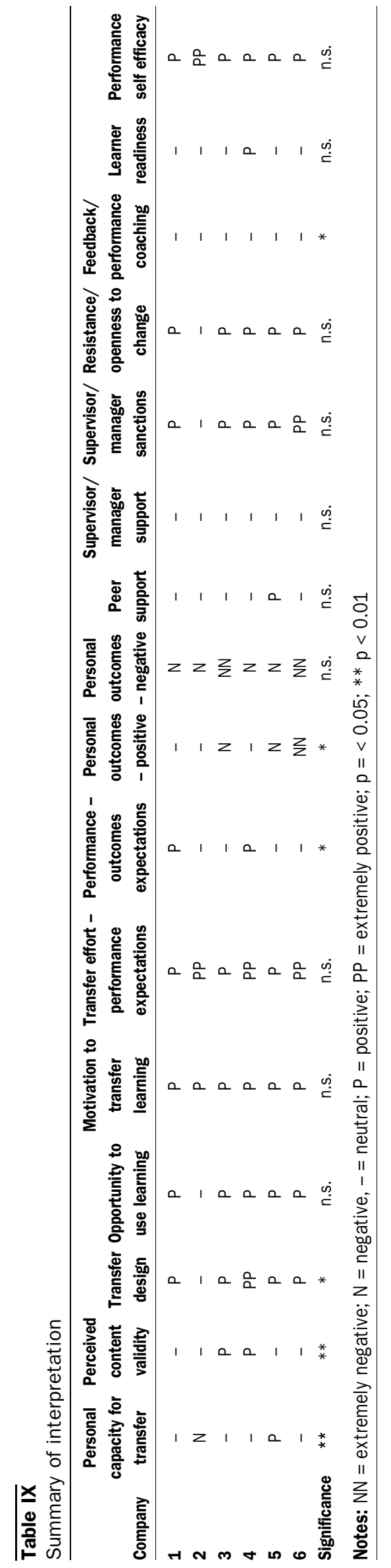


Paul Donovan, Kevin Hannigan and Deirdre Crowe

The learning transfer system approach to estimating the benefits of training: empirical evidence

Journal of European Industrial Training

25/2/3/4 [2001] 221-228 generally well run, problems often arise with the use of that learning in the workplace. In other words, training creates resources for the firm, but the firm is then unable to use those resources most effectively. Clearly, changing the training programme is not the answer to this problem. The aim is to continue this work to create a greater database of companies in different sectors. Future analysis may make sector standards or benchmarks for best practice possible.

\section{Future development}

Validation of LTSI results is on-going. To date both discussions and critical incident analyses have been conducted and the results have shown the LTSI to reflect trainees' experiences. However, qualitative differences between groups showing statistical differences need further investigation. Also, validation through comparison of LTSI results with performance measures is currently being conducted and is expected to yield more concrete results. Each organisation is expected to have variations in its optimal configuration for learning transfer because of cultural differences. Thus, the leverage points for learning transfer system improvement are expected to be both a function of deficiencies in specific factors and leverage points identified as predictive of transfer in the specific organisation. For example, managerial support, an element in the LTSI, will be more critical in some organisations than in others while peer support might be more critical in some instances. Over time perhaps optimal configurations for different types of employees and backgrounds can be elaborated as well as profiles for different industrial sectors with possibilities for benchmarking and best practice.

While to date the LTSI is used only as a diagnostic tool, it is potentially a powerful predictive tool for training outcomes. By using performance measures in combination with the LTSI to identify the key leverage factors in any organisation, the profile of the organisation may be compared with LTSI results to predict future learning transfer. The aim is to investigate whether the LTSI can provide an organisation with an indication of the likely application of learning from any particular training intervention thus enabling the organisation of take early corrective action if necessary.

\section{Conclusion}

Learning transfer systems have the potential to help close the gap between economic theory and program-level HRD evaluation. As discussed, economists have no means to model what occurs inside the "black-box" of the firm. Thus, their assessments are at the firm level or higher. HRD evaluation has traditionally been at the individual learning program/event level, aggregating upward. However, HRD evaluation has mostly ignored the other influences within the firm that affect performance outcomes from learning. The influences approach, characterised here by Holton's model, links the two by describing the system variables which intervene between program outcomes, and firm level outcome. In essence, the LTSI is not so much about evaluating training as it is about assessing how well an organisation uses the training.

The next stage in the continuing program of LTSI research is to investigate its predictive validity on the basis of organisational performance measures. This approach enhances evaluation research by demonstrating that system influences are important. In time its closer integration with existing economic models that measure the return from investment in training offers the promise of a reliable methodology for firms to evaluate and to maximise the returns from training.

\section{References}

Baldwin, T.T. and Ford, J.K. (1988), "Transfer of training: a review and directions for future research”, Personnel Psychology, Vol. 41, pp. $63-100$.

Broad, M.L. and Newstrom, J.W. (1992), Transfer of Training. Addison-Wesley, Reading, MA.

Eliasson, G. (1994), "The theory of the firm and the theory of economic growth", in Magnusson, L. (Ed.), Evolutionary and Neo-Schumpeterian Approaches to Economics, Kluwer, London, pp. 173-201.

Hannigan, K., Donovan, P., Holton, E., Bates, R. and Naquin, S. (2000), "Context and causation in the evaluation of training: relating economic and learning transfer theory", Conference Proceedings of the Academy of Human Resource Development, AHRD, Louisiana.

Holton, E.F. (1996), "The flawed four-level evaluation model", Human Resource Development Quarterly, Vol. 1, pp. 5-21.

Holton, E.F., Bates, R. and Ruona, W. (1999), "Development of a generalized learning transfer system inventory”, Human Resource Development Quarterly.

Kirkpatrick, D.L. (1996), "Revisiting Kirkpatrick's four-level model”, Training and Development, Vol. 1, pp. 54-7.

Swanson, R.A. and Holton, E.F. (1999), Results: How to Assess Performance, Learning, and Perceptions in Organizations, BerrettKoehler, San Francisco, CA. 